\section{D) Check for updates}

Cite this: Food Funct., 2021, 12, 4768

\title{
The association between carotenoids and subjects with overweight or obesity: a systematic review and meta-analysis $\uparrow$
}

\author{
Nan Yao, ${ }^{a}$ Shoumeng Yan, ${ }^{a}$ Yinpei Guo, ${ }^{a}$ Han Wang, ${ }^{a}$ Xiaotong Li, ${ }^{a}$ Ling Wang, ${ }^{a}$ \\ Wenyu Hu, ${ }^{a}$ Bo Li*a and Weiwei Cui (iD *b
}

\begin{abstract}
Background: Excess body weight, including overweight and obesity, is one of the major factors influencing human health, and plays an important role in the global burden of disease. Carotenoids serve as precursors of vitamin A-related retinoids, and are considered to have potential effects on many diseases. However, the influence of carotenoids on people with excess body weight is unclear. Methods: This meta-analysis was conducted to assess the effects of carotenoids on overweight or obese subjects utilizing the available evidence. We searched PubMed, Medline, Cochrane Library, Web of Science and EMBASE databases up to September 2020. Random effects models were used to calculate the standard mean differences (SMDs) and odds ratios (ORs) with their 95\% confidence intervals (95\% Cls). Results: A total of seven randomized controlled trials and eight observational studies met the inclusion criteria and contained 28944 subjects and data on multiple carotenoid subgroups, including lycopene, astaxanthin, cryptoxanthin, $\alpha$-carotene, and $\beta$-carotene. In all included Randomized Controlled Trial (RCT), the intervention duration was 20 days at the shortest and 16 weeks at the longest, and the range of intervention doses was $1.2-60 \mathrm{mg} \mathrm{d}^{-1}$. Our study found that the insufficiency of serum carotenoids was a risk factor for overweight and obesity (OR $=1.73,95 \% \mathrm{Cl}[1.57,1.91], p<0.001)$. Moreover, carotenoid supplementation was significantly associated with body weight reductions $(\mathrm{SMD}=-2.34 \mathrm{~kg}, 95 \% \mathrm{Cl}[-3.80,-0.87]$ $\mathrm{kg}, p<0.001$ ), body mass index decrease (BMI, SMD $=-0.95 \mathrm{~kg} \mathrm{~cm}^{-2}, 95 \% \mathrm{Cl}[-1.88,-0.01] \mathrm{kg} \mathrm{cm}^{-2}, p<$ $0.001)$ and waist circumference losses $(W C, S M D=-1.84 \mathrm{~cm}, 95 \% \mathrm{Cl}[-3.14,-0.54] \mathrm{cm}, p<0.001)$. Conclusion: In summary, the carotenoids show promising effects in overweight or obese subjects. Additional data from large clinical trials are needed.
\end{abstract}

Received 1st January 2021 Accepted 22nd April 2021 DOI: $10.1039 / \mathrm{d} 1 \mathrm{fo} 00004 \mathrm{~g}$ rsc.li/food-function
Obesity is strongly associated with the development of cardiovascular disease, type 2 diabetes, and several types of cancer, diminishing the average human life expectancy and increasing the overall burden of disease worldwide. ${ }^{4} \mathrm{~A} 5 \%$ reduction in the population's BMI levels by 2030 is estimated to decrease obesity-related direct medical expenditures by $€ 495$ million over the next 20 years. ${ }^{5}$

Carotenoids are fat-soluble pigments found in plants, fungi, bacteria, algae and human foods. ${ }^{6}$ For example, green vegetables contain large amounts of lutein, lycopene is present in mature tomatoes, chili peppers include capsaicin, and crustaceans have high levels of astaxanthin. Moreover, multiple carotenoids, such as $\beta$-carotene, are commonly found in human serum. In addition, $\alpha$-carotene, $\beta$-cryptoxanthin, lycopene, lutein and zeaxanthin have been observed. ${ }^{7}$ Notably, carotenoids are considered to have potential effects on many diseases. A positive connection between higher concentrations of carotenoids and a lower risk of chronic diseases has been illustrated by epidemiological studies, while $\beta$-carotene and 
lycopene are negatively related to the risk of cardiovascular disease. $^{8}$ Furthermore, fat-soluble carotenoids were shown to be present in lipid droplets within adipocytes and have effects on lipid absorption and transport, ${ }^{9}$ indicating a correlation between carotenoids and excess body weight. ${ }^{10}$

However, the relationship between carotenoid concentrations and subjects with overweight or obesity has not been demonstrated in meta-analyses. Carotenoid interventions were reported to cause reductions in weight, BMI and other anthropometric measures in overweight and obese people. ${ }^{11,12}$ Nevertheless, some studies have shown that carotenoid interventions have no significant effect on weight change in patients with excess body weight. ${ }^{13,14}$ The effect of carotenoids on people with excess body weight is unclear. Consequently, we conducted a meta-analysis of all related observational studies and randomized controlled trials (RCTs) to evaluate the association between carotenoids and overweight or obese subjects.

\section{Materials and methods}

\subsection{Registration}

Our study protocol was registered with the International Prospective Register of Systematic Reviews (PROSPERO, https://www.crd.york.ac.uk/PROSPERO/); registration number: CRD42020211886.

\subsection{Sources and methods of data retrieval}

We searched the PubMed, Cochrane Library, Medline, Web of Science and EMBASE databases up to September 2020, limiting to English language and human subjects, and used the keywords carotenoids, beta-carotene, alpha-carotene, cryptoxanthin, cryptoxanthin, canthaxanthin, lutein, lycopene, zeaxanthin, overweight, obesity and obese to identify published literature assessing the role of carotenoids in overweight or obese populations. The literature search was limited to reports in English and with human subjects by using the search terms ((Body Weight[Mesh] OR Weight Loss[Mesh] OR Weight Gain [Mesh] OR Body Weight Changes[Mesh] OR Body Mass Index [Mesh] OR Obesity[Mesh] OR Overweight[Mesh] OR 'body mass index' OR fitness OR 'body fatness' OR 'weight change' OR 'weight variability' OR 'weight gain' OR weight loss OR obesity OR overweight OR 'body weight' OR adiposity OR 'fat mass' OR 'body fat' OR 'body size' OR 'body composition' OR 'central obesity') AND (carotenoids OR tetraterpenes OR 'tetraterpenes derivatives' OR Derivatives, tetraterpenes OR carotene OR caroline OR beta-carotene[Mesh] OR alpha-carotene OR beta-carotene OR cryptoxanthin OR retinoids[Mesh] OR canthaxanthin[Mesh] OR lutein[Mesh] OR lycopene OR zeaxanthin OR zeaxanthin[Mesh])).

\subsection{Inclusion criteria}

Two researchers independently evaluated all studies and extracted the final eligible literature. For disagreements,
Dr Cui, who is one of the co-authors and an expert in the field of nutrition, helped discuss and solve them (Fig. 1).

2.3.1 Observational study. The inclusion criteria were as follows: (1) excess body weight, including overweight and obesity, was defined on a local criterion. (2) The carotenoid concentration was measured by serum carotenoid concentration. (3) The results must include quantitative data with odds ratios (ORs) and their 95\% confidence intervals (95\% CIs) to evaluate the risk of insufficient carotenoids between subjects with excess body weight and the normal weight subjects. Studies that did not provide initial data, animal studies, duplicate literature, in vitro studies, reviews, or conference papers were excluded.

2.3.2 Randomized controlled trials. The inclusion criteria were as follows: (1) RCTs compared the carotenoid intervention and noncarotenoid intervention groups; (2) overweight or obesity was defined based on a local criterion; and (3) the outcomes were quantitative data that could be extracted or calculated.

Exclusion criteria were as follows: (1) single-arm studies or without a placebo or a mixture of carotenoid and antioxidant intervention or unquantifiable doses of carotenoid intervention; (2) patients with cancer, pregnancy and any other medication that could influence the carotenoid concentrations; and (3) nonhuman studies, reviews and conference literature.

\subsection{Data abstraction}

2.4.1 Observational study. All included studies were assessed, and the following data were extracted: (1) first author, nationality, publication year, numbers, mean age, BMI, and sex of individuals in the case/supplementation groups and controls; (2) the carotenoids type and subject type; and (3) the indicator to evaluate the risk for insufficient carotenoid concentration: ORs and their 95\% CIs.

2.4.2 Randomized controlled trials. Studies were included if they provided the following criteria: (1) first author, nationality, publication year, numbers, mean age and sex of carotenoids intervention subjects and the controls; (2) the carotenoids type, subject type, intervention time and dose; and (3) the variations in the body weight, BMI, waist circumference (WC), total cholesterol (TC), low-density lipoprotein (LDL), high density lipoprotein cholesterol (HDL), and triglycerides (TG) in the carotenoids intervention and control subjects.

\subsection{Risk of bias within individual studies}

Cochrane Collaboration (RevMan version 5.3) software was used to estimate the risk of bias for RCTs. Moreover, the Newcastle-Ottawa scale (NOS), a scale for assessing the quality of published nonrandomized studies in meta-analyses, ${ }^{15}$ was used to estimate the risk of bias (including selection, comparability, and exposure) for the observational studies.

\subsection{Statistical analysis}

Statistical analysis was performed using the statistical software RevMan version 5.3 and Stata version 12.0. The figures in the observational studies were collected to calculate the ORs and 

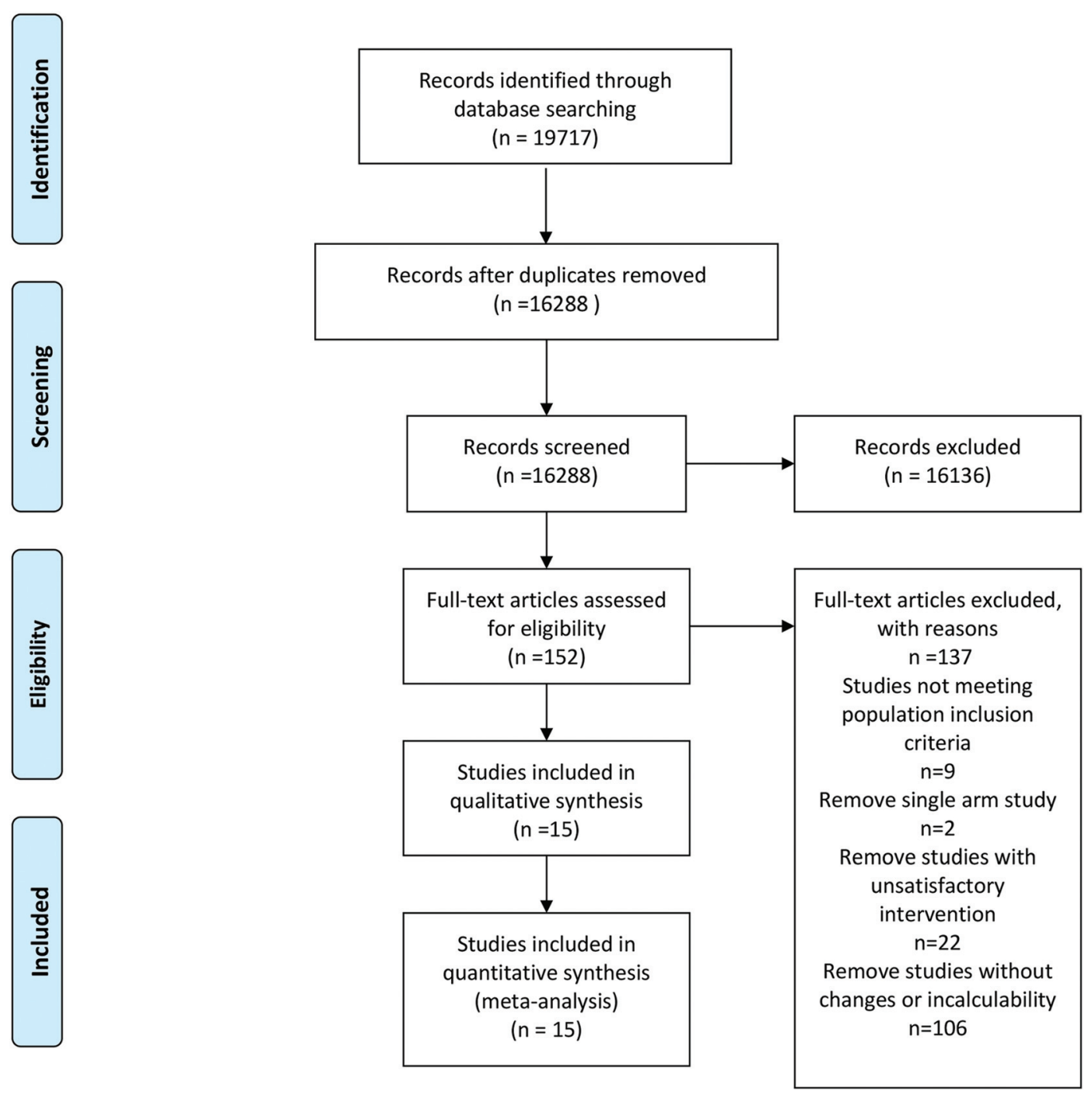

Fig. 1 Flow diagram of the literature search and selection.

95\% CIs by the random effects model, while the data from all of the individual RCTs were used to calculate the standard mean difference (SMD) and 95\% CIs using the random effects model. We calculated the standard deviations of the mean changes in the anthropometric and metabolic parameters that were unavailable from the original literature using the equations in the Cochrane Handbook. Correlation coefficients of the equations were evaluated from the data in the included literature that simultaneously provided baseline and endpoint values and variations.

$$
\sqrt{\mathrm{SD}_{\text {Baseline }}{ }^{2}+\mathrm{SD}_{\text {Final }^{2}}-2 \times 0.98 \times \mathrm{SD}_{\text {Baseline }} \times \mathrm{SD}_{\text {Final }}}
$$

Cochran's Q statistic and the $\mathrm{I}^{2}$ statistic were used to evaluate the statistical heterogeneity. $p<0.05$ was defined as significant for heterogeneity. Egger's test was used to calculate the publication bias. The potential publication bias was evaluated via Egger's test, where the trim-and-fill method (sensitivity analysis) was used to correct outcomes and evaluate the impact of bias on the outcomes.

For the observational studies, the subgroup analyses were conducted based on the age $(<18$ years and $\geq 18$ years), sex of the subjects (male, female and both of male and female), region (Asia, South America, North America and Oceania), population type (overweight and obesity) and carotenoid type (lycopene, astaxanthin, cryptoxanthin, zeaxanthin/lutein, $\alpha$-carotene, $\beta$-carotene, total carotenoids and lutein/zeaxanthin).

Additionally, we used subgroup analyses based on the intervention time ( $\leq 12$ weeks and $>12$ weeks), region (Asia and Europe), population type (overweight: $25 \mathrm{~kg} \mathrm{~cm}^{-2} \leq \mathrm{BMI}<$ $30 \mathrm{~kg} \mathrm{~cm}{ }^{-2}$, obesity: BMI $>30 \mathrm{~kg} \mathrm{~cm}^{-2}$, and both overweight and obesity: BMI $>30 \mathrm{~kg} \mathrm{~cm}^{-2}$ ) and population sex (male, female and both of male and female) to evaluate the source of heterogeneity for the RCTs. 


\section{Results}

Only 15 studies of the 19717 relevant publications evaluated met the inclusion criteria, and contained a total of 28944 subjects. ${ }^{11-14,16-26}$ These 15 articles included 8 papers analysing differences in the serum carotenoid concentrations between subjects with excess body weight and the normal weight subjects, ${ }^{19-26}$ and 7 papers (RCTs) evaluating the change in the anthropometric and blood liquid parameters in response to supplementation with carotenoids. ${ }^{11-14,16-18}$ Detailed information and primary outcome parameters are presented in Tables 1 and 2, and the risk of bias within individual studies for RCTs is shown in Fig. S1 and Table S1. $\dagger$

\subsection{Risk of low carotenoid concentrations}

For the 8 papers analysing serum carotenoid concentrations to determine whether low carotenoid concentrations were a risk factor for obesity, 2 studies were conducted in Asia, ${ }^{23,25} 2$ studies were performed in North America, ${ }^{20,26} 3$ studies were performed in South America ${ }^{19,21}$ and 1 study was performed in Oceania. $^{24}$ Three studies were conducted in the adults (age $\geq 18$ years (ref. 23, 25 and 26)) and 4 studies focused on adolescents and children (age <18 years (ref. 19-22)), and the remaining 1 paper was not analysed because this article did not state the age of the subjects. The population was overweight in 5 studies $^{19-21,24,26}$ and obese in 5 studies. $^{20,22-26}$ Four studies were carried out among the male population, ${ }^{19,23,25,26} 4$ studies were undertaken with female subjects, ${ }^{23,25,26}$ and the rest of the studies had both male and female subjects. ${ }^{20-22,24}$ The studies were divided into 8 subgroups according to carotenoid species; the lycopene group contained 3 studies, ${ }^{23,25,26}$ and the astaxanthin group included 1 study. ${ }^{23}$ The type of carotenoid was cryptoxanthin in 3 studies, ${ }^{23,25,26}$ zeaxanthin/lutein in 2 studies, ${ }^{23,25,26} \alpha$-carotene in 4 studies, ${ }^{20,23,25,26} \beta$-carotene in 5 studies, ${ }^{19,20,23,25,26}$ total carotenoids in 3 studies ${ }^{21,22,24}$ and lutein/zeaxanthin in 1 study. ${ }^{26}$ The risk of bias within studies analysing whether low carotenoid concentrations were a risk factor by the NOS is demonstrated in Table S2. $\dagger$ Furthermore, the GRADE system was utilized to evaluate the quality of evidence (Table S3†).

We performed a meta-analysis of the carotenoid concentration to evaluate whether low carotenoid concentrations were a risk factor in obese or overweight people. Low serum carotenoid levels were a risk factor for overweight or obese subjects compared to control subjects ( OR $=1.73$, 95\% CI $[1.57,1.91], p$ $<0.001$ ) (Fig. 2). Moreover, publication bias was not observed in the serum carotenoid concentration, as shown by Egger's test (coefficient $=-0.5664128, t=-0.95, p=0.346$ ).

In addition, we performed subgroup analysis based on the age, sex, region, population type, and carotenoid type. Studies were subdivided into two groups: the adults (age $\geq 18$ years) and the minors (age $<18$ years). For both groups, the risk of insufficient serum carotenoid concentration was higher in the subjects with excess weight than the normal. Moreover, the subgroup analysis was conducted to determine if there were differences in the effects of the region: Asia, South America,
North America and Oceania. The risk of insufficient serum carotenoid concentration for the subjects with excess weight was higher than that for the normal weight subjects in the Asia group and the North America group. Based on the gender distribution of the subjects included, all studies were divided into three categories: male, female, and both male and female. The risk of low serum carotenoid concentrations was higher in all of the groups than in the controls. Moreover, studies were classified into two groups (overweight and obese) based on the BMI of the subjects. For the two groups, we observed a statistically significant difference between the two groups compared to the control group. In addition, the types of carotenoids in the included studies were lycopene, astaxanthin, cryptoxanthin, zeaxanthin/lutein, $\alpha$-carotene, $\beta$-carotene, total carotenoids and lutein/zeaxanthin. The risk of low serum carotenoid concentrations was higher than that of the controls in all of the groups, except the astaxanthin group and total carotenoid group. In summary, subgroup analyses indicated that region and carotenoid type may contribute to the heterogeneity of the results (Table 3 ).

\subsection{Effect of carotenoid supplementation}

A total of 7 studies evaluated the change in anthropometric and blood liquid parameters, involving 498 samples, with 255 interventions and 243 controls. We evaluated variations in weight, BMI, WC, fat ratio, TC, TGs, LDL, and HDL in six, five, five, two, two, four, three and two papers, respectively. The detailed figures are presented in Table 4. Furthermore, to assess the quality of evidence, we used the GRADE system (Table 4). The meta-analysis demonstrated that carotenoid interventions in people who are overweight or obese might contribute to their weight reduction $(\mathrm{SMD}=-2.34 \mathrm{~kg}, 95 \% \mathrm{CI}$ $[-3.80,-0.87] \mathrm{kg}, p<0.001$, Fig. 3). Carotenoid intervention resulted in a significantly larger reduction in BMI (SMD =

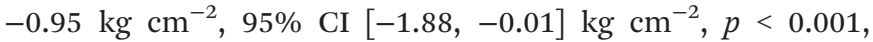
Fig. 4), WC (SMD = -1.84 cm, 95\% CI $[-3.14,-0.54] \mathrm{cm}, p<$ 0.001 , Fig. 5) and TC (SMD $=-2.095 \mathrm{mg} \mathrm{dL}^{-1}, 95 \%$ CI $[-3.201$, -0.989 ], $p<0.001$, Table 5). Additionally, statistically significant differences in the variation in HDL were also observed $\left(\mathrm{SMD}=0.757 \mathrm{mg} \mathrm{dL}{ }^{-1}, 95 \%\right.$ CI $[0.101,1.413], p=0.024$, Table 5). Nevertheless, the data included in this meta-analysis did not show any significant effect of carotenoids on the fat ratio, or LDL and TG concentrations (Table 5). The details of the subgroup analysis for the carotenoid intervention and the changes in the anthropometric and lipid parameters in overweight or obese individuals are summarized in Table S4. $\dagger$ Population weight may be the source of heterogeneity for the body weight, BMI, and WC. Intervention time, region and population sex may be the sources of heterogeneity for TGs.

The publication bias outcomes of the included studies are presented in Table S5.† Publication biases were observed in body weight and LDL $(\mathrm{P}<0.05)$. However, there was no significant difference in SMD before and after trimming and filling. Therefore, the influence of publication bias was considered slight and the results were stable (Table S5 $\dagger$ ). 
क क्र

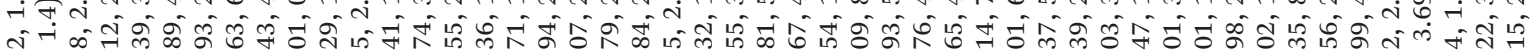
¿̇

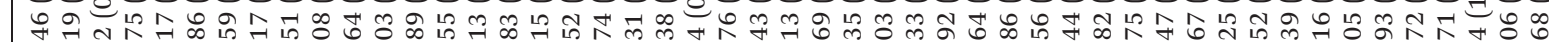
茂

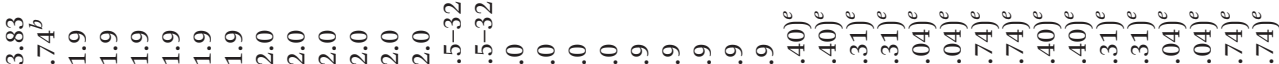

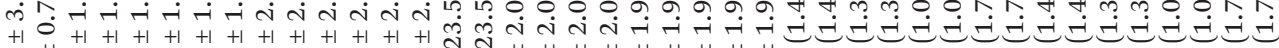

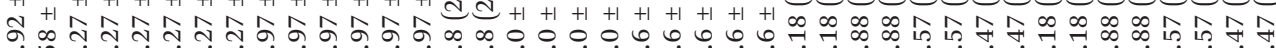

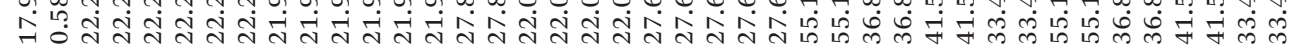

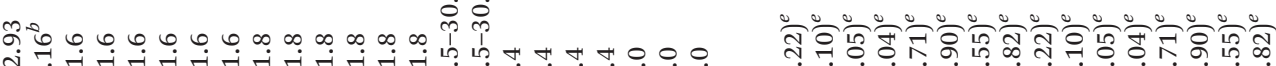

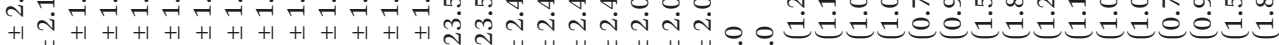

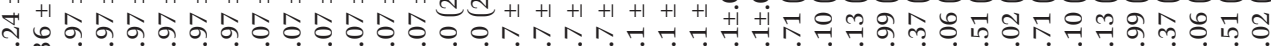

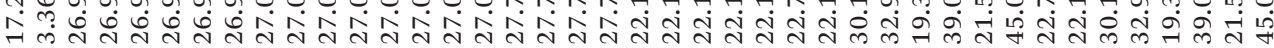

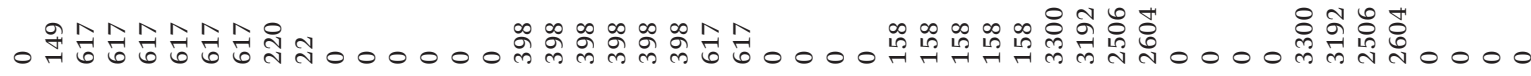

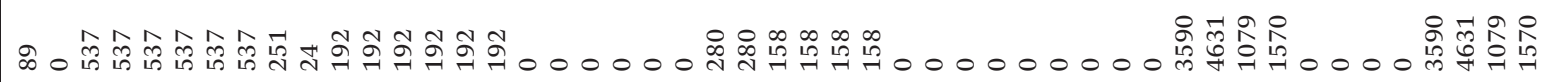

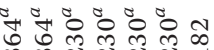
현

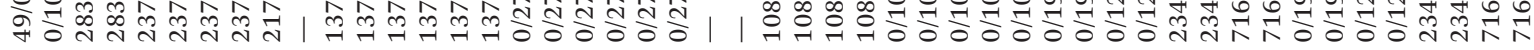

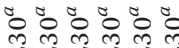

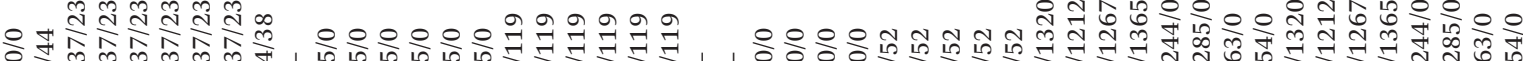

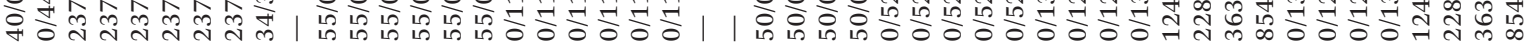

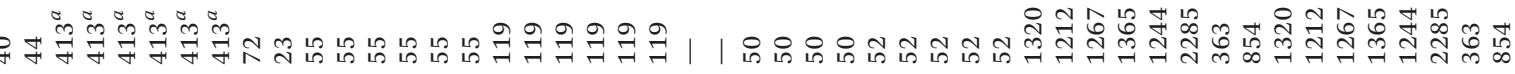
亏气े

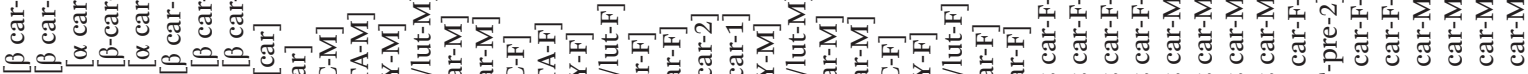

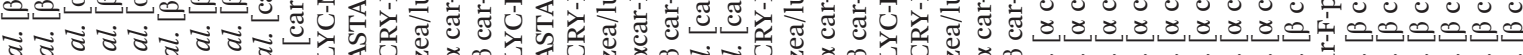

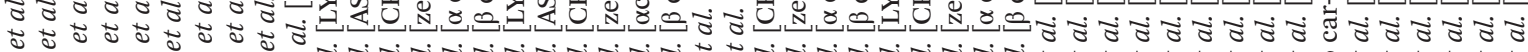




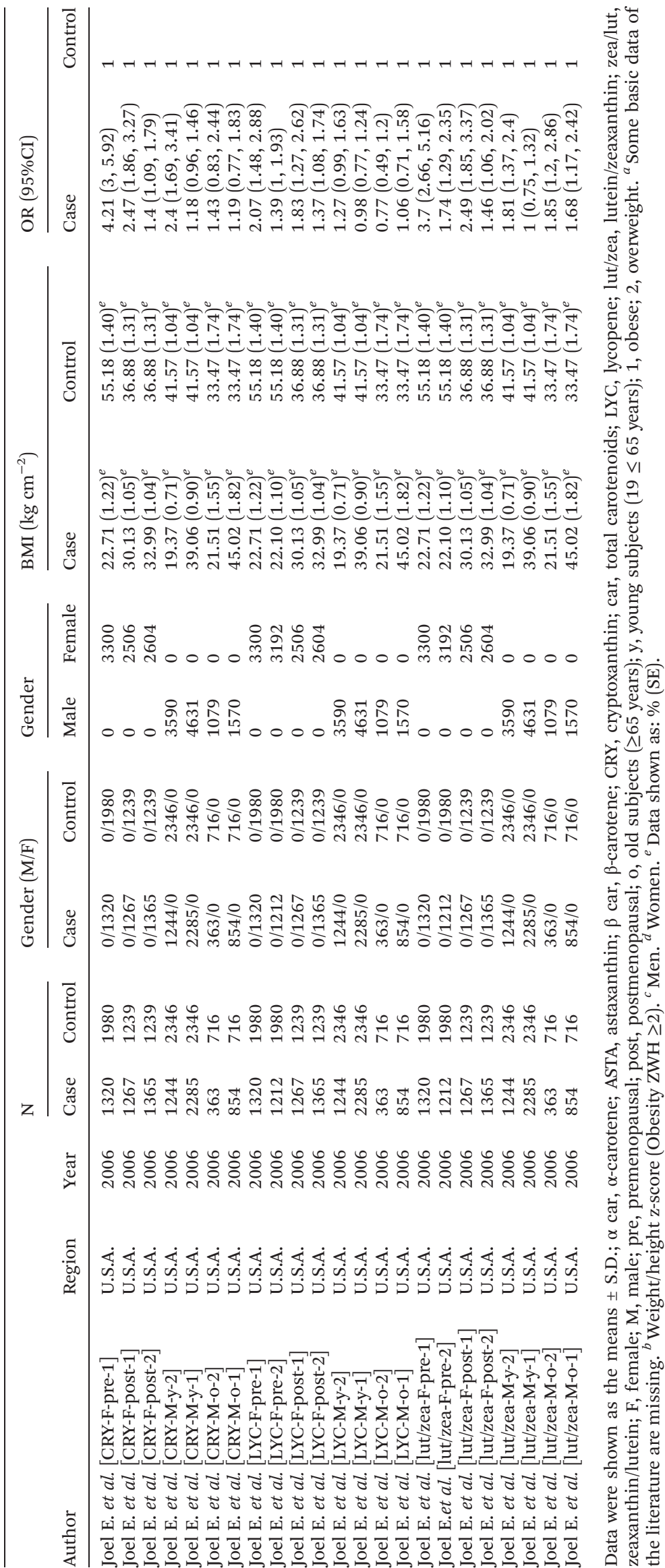




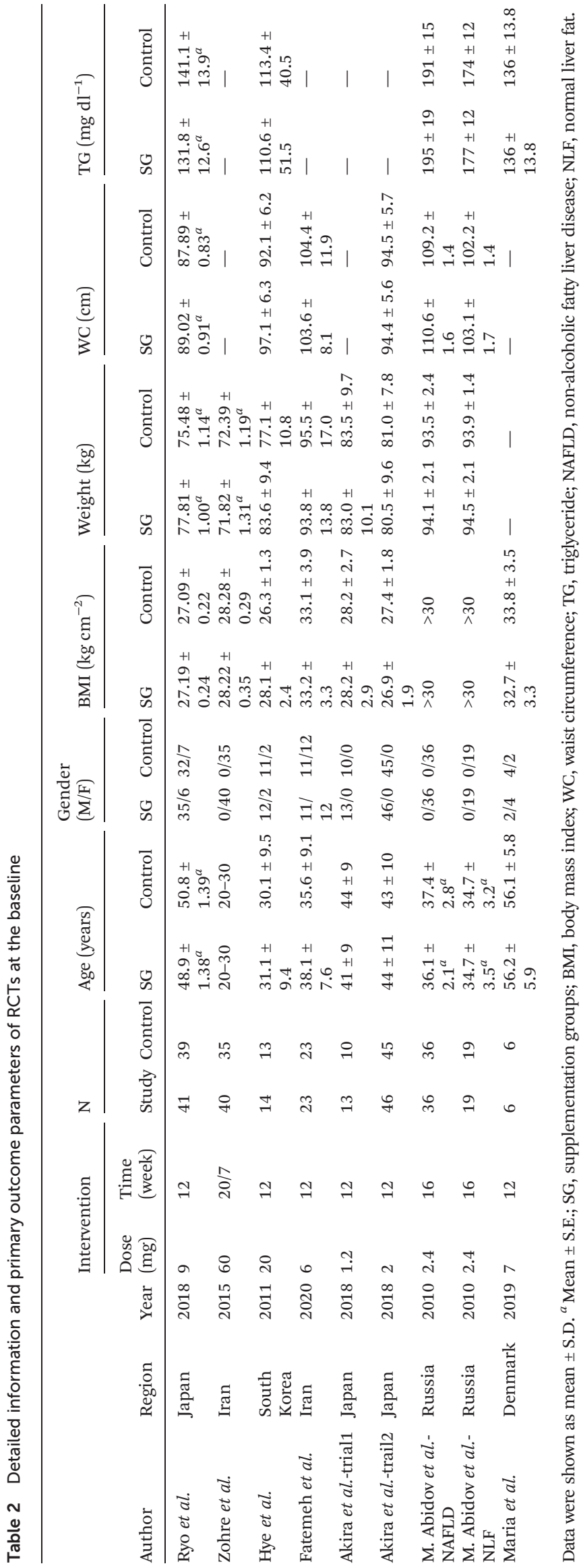

\section{Discussion}

In our research, in addition to the international standards to define overweight and obesity, two definitions by local standards were used. First, overweight was defined as BMI for AGE $>$ Z-score +1 and $\leq+2$ and obese as BMI for AGE $>$ Z-score +2 . Second, BMI-for-age percentiles $\geq 85$ th-95th percentiles were considered as overweight and BMI-for-age percentiles $\geq 95$ th percentiles were considered obese. Studies have found that obese people, both adults and children, have low blood carotenoid concentrations. ${ }^{2,27,28}$ Similar to these studies, our meta-analysis showed that the low serum carotenoids levels are associated with obesity and are a risk factor for obesity. This finding might be due to retinoids, known as the intermediate products of vitamin A metabolism, ${ }^{29}$ mainly retinol, retinal and retinoic acid, which can exert antiobesity effects. ${ }^{30,31}$ Retinoids are considered to block the formation of adipocytes, decrease fat accumulation, and be involved in the inflammatory response. The possible mechanisms of retinoids against obesity are mainly as follows: (1) Retinoids blocked the formation of adipocytes. Retinoic acid-liganded RARs (retinoic acid receptors) block the transcription of CCAAT/enhancerbinding protein- $\alpha(\mathrm{C} / \mathrm{EBP} \alpha)$, which is required for adipogenesis. ${ }^{32}$ Moreover, these molecules block the induction of peroxisome proliferator-activated receptor $\gamma(\operatorname{PPAR} \gamma)$, a key transcription factor needed for fat accrual in adipocytes. ${ }^{33}$ (2) Retinoids decreased fat accumulation. White adipose tissue (WAT) stores excess energy as triglycerides, while brown adipose tissue (BAT) specializes in the dissipation of fat through the production of heat. ${ }^{34}$ According to previous reports, there is a phenomenon named WAT-TO-BAT remodelling or browning of white fat, ${ }^{35}$ which is represented by brite or beige adipocytes appearing in WAT depots in the mammalian body under conditions of thermogenic activity, leading to fat breakdown. ${ }^{36,37}$ In this process, UCP1 (uncoupling protein1), the key protein needed for uncoupling mitochondrial respiration, plays an important role, resulting in reduced fat accumulation in WAT. ${ }^{38}$ Furthermore, retinoic acid increases the gene expression of UCP1 through the mediation of RARs. $^{36,39}$ (3) Retinoids are involved in the inflammatory response. Increased macrophage infiltration of adipose tissue plays a critical role in metabolic disease development, while retinoic acid was found to significantly diminish $\mathrm{NF}-\kappa \mathrm{B}$ (nuclear factor kappa-B) activation and decrease macrophage infiltration of the epididymal fat. ${ }^{40,41}$ Carotenoids, such as $\beta$-carotenoids, are considered to be the precursors of retinoids in some research, ${ }^{7}$ indicating that when carotenoid levels in the body decrease, the synthesis of retinoids is reduced, thus affecting the body's ability to prevent obesity. Similarly, according to the result of subgroup analysis with carotenoid type, we observed that compared to that of the normal weight population, the OR of low $\beta$-carotenoids in the obese or overweight population was higher than that of the other types. Furthermore, a decrease in heterogeneity was noted in this subgroup analysis. In summary, we found that low serum carotenoid status is a risk factor for obesity. Therefore, 


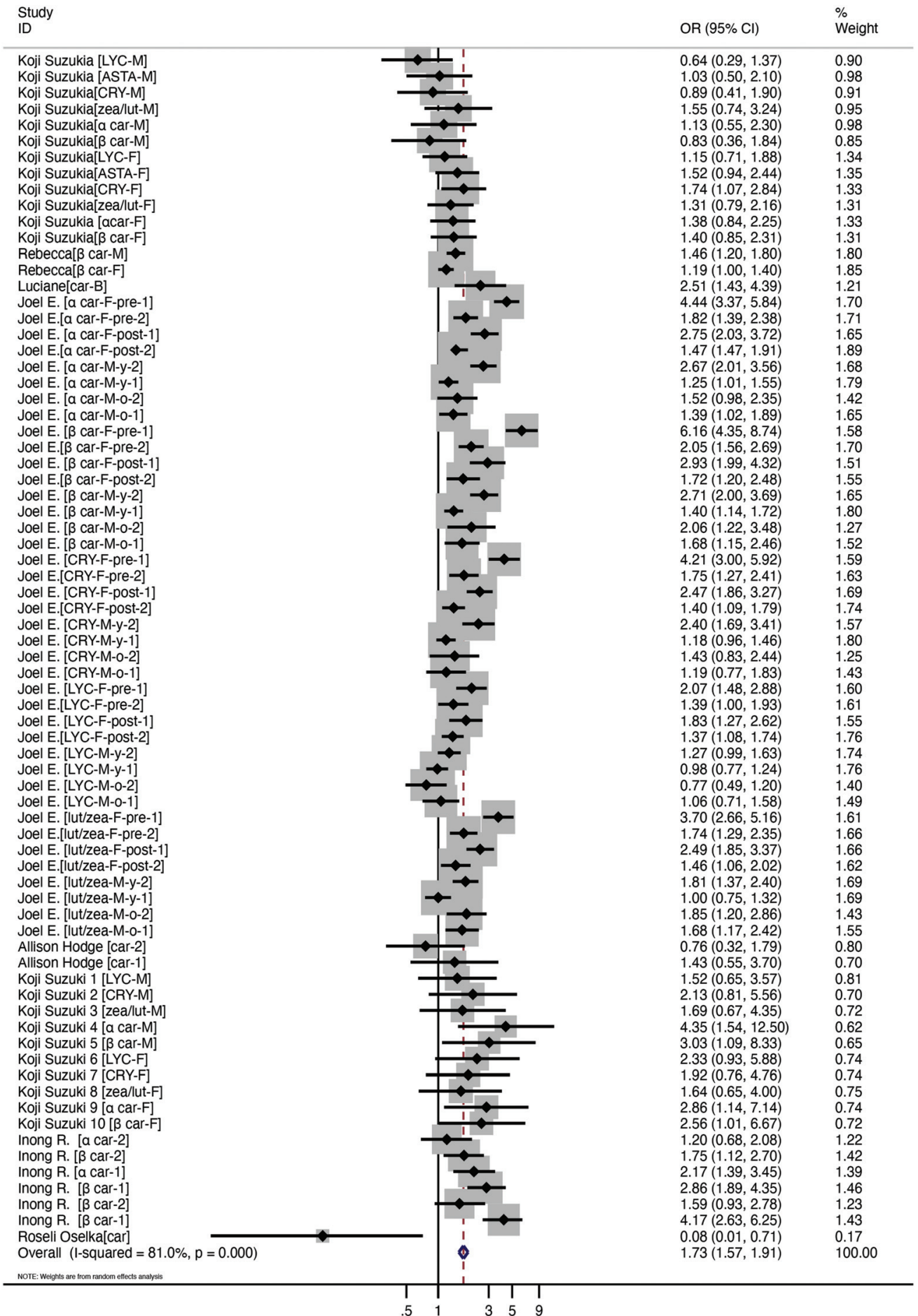

Fig. 2 Meta-analysis results of the serum carotenoid concentration in the subjects with obesity or overweight vs. the control subjects.

carotenoid supplementation should be considered for obese individuals.

Available animal and human studies have identified a positive role for carotenoids in weight loss. ${ }^{11,42}$ Such findings are analogous to the conclusions of our study. We concluded that the overweight and obese population with carotenoid intervention had a significant decrease in anthropometric measures (weight, WC and BMI), compared to the control population. A critical mechanism contributing to these beneficial effects appears to be the "abnormal immune response" in obesity. Calder et al. proposed that the obesity is highly correlated with low-grade inflammation, ${ }^{43}$ in which adipose tissue releases many inflammatory mediators. ${ }^{44,45}$ When carotenoids are sufficient due to the intervention, the circulating concen- 
Table 3 Subgroup analyses for observational studies

\begin{tabular}{|c|c|c|c|}
\hline Grouped by & No. of studies & OR $(95 \% \mathrm{CI}), P$ & $I^{2}(\%), P$ \\
\hline \multicolumn{4}{|l|}{ Age } \\
\hline$\geq 18$ & 62 & $1.733(1.553,1.932),<0.001$ & $81.4,<0.001$ \\
\hline$<18$ & 10 & $1.821(1.359,2.442),<0.001$ & $82.2,<0.001$ \\
\hline \multicolumn{4}{|l|}{ Gender } \\
\hline Male & 32 & $1.449(1.280,1.640),<0.001$ & $68.5,<0.001$ \\
\hline Female & 32 & $1.995(1.711,2.327),<0.001$ & $85.2,<0.001$ \\
\hline Male and female & 10 & $1.829(1.295,2.583), 0.001$ & $71.2,<0.001$ \\
\hline \multicolumn{4}{|l|}{ Region } \\
\hline Asia & 22 & $1.457(1.250,1.698),<0.001$ & $6.9,0.368$ \\
\hline South America & 4 & $1.413(0.988,2.021), 0.058$ & $77.1,0.004$ \\
\hline North America & 46 & $1.850(1.636,2.091),<0.001$ & $86.2,<0.001$ \\
\hline Oceania & 2 & $1.005(0.531,1.905), 0.987$ & $0,0.334$ \\
\hline \multicolumn{4}{|l|}{ BMI } \\
\hline Overweight & 27 & $1.621(1.465,1.795),<0.001$ & $84.7,<0.001$ \\
\hline Obesity & 47 & $1.800(1.532,2.114),<0.001$ & $64.6,<0.001$ \\
\hline \multicolumn{4}{|l|}{ Type } \\
\hline LYC & 12 & $1.278(1.070,1.525), 0.007$ & $60.7,0.003$ \\
\hline ASTA & 2 & $1.349(0.907,2.007), 0.139$ & $0,0.376$ \\
\hline CRY & 12 & $1.766(1.365,2.284),<0.001$ & $81,<0.001$ \\
\hline zea/lut & 4 & $1.459(1.027,2.071), 0.035$ & $0,0.948$ \\
\hline$\alpha$ car & 14 & $1.902(1.504,2.404),<0.001$ & $85.4,<0.001$ \\
\hline$\beta$ car & 18 & $2.050(1.639,2.564),<0.001$ & $85.9,<0.001$ \\
\hline car & 4 & $1.024(0.393,2.669), 0.962$ & $74.6,0.008$ \\
\hline lut/zea & 8 & $1.835(1.394,2.415),<0.001$ & $83.0,<0.001$ \\
\hline
\end{tabular}

BMI, body mass index; LYC, lycopene; ASTA, astaxanthin; CRY, cryptoxanthin; zea/lut, zeaxanthin/lutein; $\alpha$ car, $\alpha$-carotene; $\beta$ car, $\beta$-carotene; car, total carotenoids; lut/zea, lutein/zeaxanthin.

Table 4 The summary of findings (SoF) with the GRADE system

Carotenoid intervention compared to no carotenoid intervention for subjects with overweight or obesity

Population: Subjects with overweight or obese

Settings: Two studies were conducted in Europe, five studies were conducted in Asia

Intervention: Carotenoid intervention

Comparison: No carotenoid intervention

\begin{tabular}{|c|c|c|c|}
\hline Outcomes & $\operatorname{SMD}(95 \% \mathrm{CI})^{a}$ & No. of participants (studies) & Quality of the evidence comments (GRADE) \\
\hline $\mathrm{WC}(\mathrm{cm})$ & $-1.840(-3.140,-0.540)$ & 388 (5RCTs) & $\oplus \oplus \ominus \ominus \mathrm{Low}^{b, c}$ \\
\hline $\mathrm{TG}\left(\mathrm{mg} \mathrm{dL} \mathrm{L}^{-1}\right)$ & $-2.095(-3.201,-0.989)$ & 263 (4RCTs) & $\oplus \oplus \oplus \ominus$ Moderate ${ }^{b}$ \\
\hline $\mathrm{TC}\left(\mathrm{mg} \mathrm{dL} \mathrm{L}^{-1}\right)$ & $-2.095(-3.201,-0.989)$ & 119 (3RCTs) & $\oplus \oplus \oplus \ominus$ Moderate ${ }^{b}$ \\
\hline $\operatorname{LDL}\left(\mathrm{mg} \mathrm{dL}^{-1}\right)$ & $-1.300(-3.225,0.625)$ & 119 (3RCTs) & $\oplus \oplus \oplus \ominus$ Moderate ${ }^{b}$ \\
\hline
\end{tabular}

GRADE working group grades of evidence

High quality: We are very confident that the true effect lies close to that of the estimate of the effect

Moderate quality: We are moderately confident in the effect estimate: the true effect is likely to be close to the estimate of the effect, but there is a possibility that it is substantially different

Low quality: Our confidence in the effect estimate is limited: the true effect may be substantially different from the estimate of the effect Very low quality: We have very little confidence in the effect estimate: the true effect is likely to be substantially different from the estimate of effect

SMD: standard mean deviation; CI: confidence interval; RCT: randomized controlled trial; WC: waist circumference; BMI: body mass index; TG: triglycerides; TC: total cholesterol; LDL: low density lipoprotein; HDL: high density lipoprotein. ${ }^{a}$ Results for variations of treatments compared with controls. ${ }^{b}$ Bias risk: downgraded by one level, as most of the included literature did not perform the Blind method allocation scheme hiding. ${ }^{c}$ Inconsistency: downgraded by one level, as a high heterogeneity existed and its source was not completely clear.

trations of inflammatory markers declined, which improves the state of obesity. Additionally, Thomas-Valdés and Bohn revealed a very powerful connection between oxidative stress and obesity. Oxidative stress triggers obesity by several mechanisms, such as stimulating the deposition of WAT, enhancing the proliferation and differentiation of preadipocytes and 
Study

ID
$\operatorname{SMD}(95 \% \mathrm{Cl})$

Weight

\begin{tabular}{|c|c|c|c|}
\hline M. Abidov-NAFLD & $\rightarrow$ & $-4.30(-5.14,-3.45)$ & 12.62 \\
\hline M. Abidov-NLF & & $-12.68(-14.83,-10.53)$ & 10.26 \\
\hline Ryo Kakutani1 & & $-3.29(-3.96,-2.61)$ & 12.81 \\
\hline Zohre Pourahmadi MSc & & $0.36(-0.10,0.82)$ & 13.01 \\
\hline Hye Duck Choi & & $-0.71(-1.49,0.07)$ & 12.70 \\
\hline Fatemeh Haidari & & $-0.03(-0.61,0.55)$ & 12.91 \\
\hline Akira Iwata-trial1 & & $-0.11(-0.94,0.71)$ & 12.65 \\
\hline Akira Iwata-trail2 & & $-0.08(-0.49,0.33)$ & 13.04 \\
\hline Overall $(I-$ squared $=97.5 \%, p=0.000)$ & & $-2.34(-3.80,-0.87)$ & 100.00 \\
\hline NOTE: Weights are from random effects analysis & & & \\
\hline
\end{tabular}

Fig. 3 Meta-analysis results of carotenoid supplementation for body weight in overweight or obese subjects.

Study

ID
$\%$

$\operatorname{SMD}(95 \% \mathrm{Cl}) \quad$ Weight

\begin{tabular}{|c|c|c|}
\hline Ryo Kakutani1 & $-3.46(-4.16,-2.76)$ & 16.46 \\
\hline Zohre Pourahmadi MSc, & $0.00(-0.45,0.45)$ & 17.38 \\
\hline Hye Duck Choi & $-0.79(-1.58,-0.01)$ & 16.06 \\
\hline Fatemeh Haidari & $0.00(-0.58,0.58)$ & 16.95 \\
\hline Akira Iwata-trial1 & $-0.87(-1.73,-0.00)$ & 15.69 \\
\hline Akira Iwata-trail2 & $-0.66(-1.08,-0.24)$ & 17.47 \\
\hline Overall $($ I-squared $=93.3 \%, p=0.000)$ & $-0.95(-1.88,-0.01)$ & 100.00 \\
\hline NOTE: Weights are from random effects analysis & & \\
\hline
\end{tabular}

Fig. 4 Meta-analysis results of carotenoid supplementation for BMI in overweight or obese subjects.

increasing the size of mature adipocytes. ${ }^{46}$ Carotenoids are essential in regulating oxidative metabolism and reducing cellular differentiation to treat obesity. ${ }^{47}$ Moreover, the association between the nuclear receptor superfamily and carotenoids may provide a mechanism for the antiobesity effect of carotenoids. Carotenoids, such as $\beta$-carotenoids, can be con- verted to retinoic acids ${ }^{48}$ in their all-trans or 9-cis configuration, which are highly-potent activators of the retinoic acid receptors (RARs) and the retinoid-X receptors (RXRs). ${ }^{49}$ Among them, all-trans retinoic acid (atRA) is known to have an inhibitory effect on adipogenesis. ${ }^{48}$ Several mechanisms could explain the inhibition of adipogenesis by atRA. One mecha- 
Study

ID
$\%$

$\operatorname{SMD}(95 \% \mathrm{Cl})$

Weight

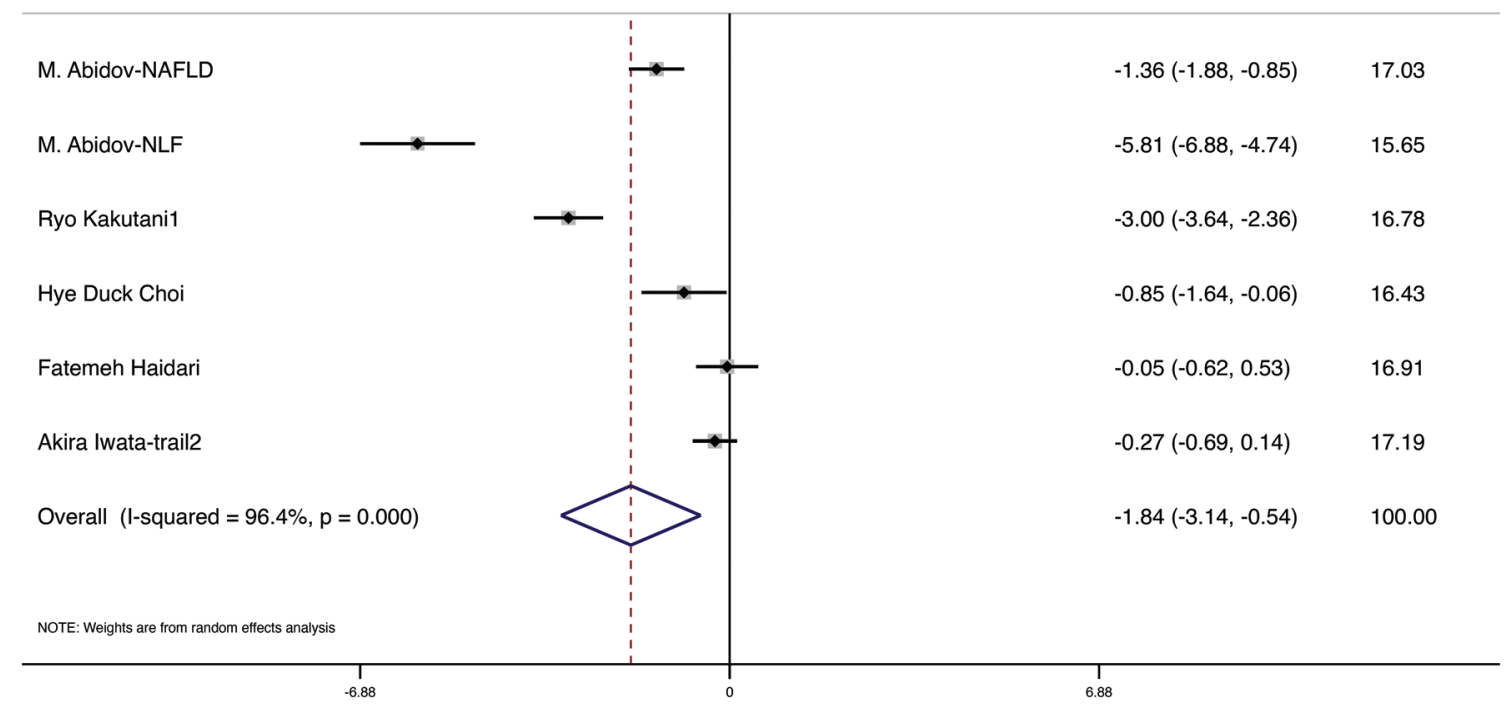

Fig. 5 Meta-analysis results of carotenoid supplementation for WC in subjects with overweight or obesity.

Table 5 Meta-analysis results of the fat ratio, HDL, LDL, TC and TG

\begin{tabular}{llll}
\hline Factors & Numbers of studies & SMD $(95 \% \mathrm{CI}), P$ & $I^{2}(\%), P$ \\
\hline Fat ratio $(\%)$ & 2 & $-0.754(-1.762,0.254), 0.143$ & $90.1,0.001$ \\
HDL $\left(\mathrm{mg} \mathrm{dL}^{-1}\right)$ & 2 & $0.757(0.101,1.413), 0.024$ & $0,0.465$ \\
LDL $\left(\mathrm{mg} \mathrm{dL}^{-1}\right)$ & 3 & $-1.300(-3.225,0.625), 0.186$ & $90.7,<0.001$ \\
TC $\left(\mathrm{mg} \mathrm{dL}^{-1}\right)$ & 2 & $-2.095(-3.201,-0.989),<0.001$ & $72,0.059$ \\
TG $\left(\mathrm{mg} \mathrm{dL}^{-1}\right)$ & 4 & $-1.875(-4.382,0.632), 0.143$ & $96.9,<0.001$
\end{tabular}

SMD: standard mean difference; LDL, low density lipoprotein; HDL, high density lipoprotein; TC, total cholesterol; TG, triglyceride.

nism involves atRA inhibition of the function of the early adipogenic transcription factor CCAAT/enhancer-binding protein$\beta(\mathrm{C} / \mathrm{EBP} \beta)$ in the adipogenic program through RAR-dependent induction of the $\mathrm{C} / \mathrm{EBP} \beta$ inhibitory protein $\operatorname{Smad} 3 .^{50}$ In addition, atRA uses the RAR pathway in preadipocytes to generate specific proteins that inhibit adipogenesis. ${ }^{51}$ Moreover, atRA could be an effective signal for the transcription of the prolipolytic substance UCP1 gene, inducing the expression of UCP1 through the mediation of RXRs. ${ }^{52,53}$ For these reasons, carotenoids have the potential to influence the regulation of obesity and related metabolic parameters.

Lipid metabolic disorders are intimately connected to the development of cardiovascular disease. High-density lipoprotein (HDL) is considered a protective indicator of cardiovascular events ${ }^{54,55}$ while high levels of serum total cholesterol (TC) are regarded as a risk factor. ${ }^{56}$ Our meta-analysis identified a significant increase in HDL and a decrease in TC parameters in the carotenoid intervention group compared to the control group, indicating that carotenoids can prevent cardiovascular disease. Under low-grade inflammation in patients with hyperli- pidaemia, inflammatory factors (Serum Amyloid A Protein, SAA) change HDL into a nonfunctional type by replacing apolipoprotein AI in HDL. ${ }^{57}$ Nonfunctional HDL is considered to be incapable of catabolizing excess lipids, struggling to maintain the normal serum TC levels and increasing the risk of cardiovascular disease. However, carotenoids have the ability to reverse this phenomenon by reducing HDL3-associated SAA, transforming $\mathrm{HDL}_{2 \& 3}$-associated enzymes PON-1 (paraoxonase1) and LCAT (lecithin: cholesterol acyltransferase), and ultimately releasing HDL from SAA. ${ }^{58}$ Additionally, carotenoids can regulate insulin resistance or insufficient secretion, which is one of the reasons why obesity contributes to abnormal lipid metabolism. ${ }^{59}$ This deficiency probably results from activation of the NF-KB transcription factor by TNF- $\alpha$ (tumour necrosis factor- $\alpha$ ), and carotenoids could decrease the reactivation. In conclusion, carotenoids play an important role in multiple stages of the lipid metabolic process. ${ }^{60}$ Considering the correlation between dyslipidaemia and coronary heart disease, the effective intervention of carotenoids in dyslipidaemia discovered in this study is estimable to some extent. 
In accordance with the outcomes of the subgroup metaanalysis, the anthropometric parameters in the female group, including body weight and TGs, were significantly reduced in terms of SMD values compared to those of the female and male group. The mechanism might be related to oestrogen, a potent steroid hormone with higher concentrations in females from adolescence to menopause than in males. ${ }^{61}$ An animal experiment conducted by Clegg exploring the association between sex hormones and leptin sensitivity has demonstrated that oestrogen increases the expression of UCP1 mRNA, ultimately leading to an increase in brown adipocyte breakdown and a reduction in body weight. ${ }^{62}$ We conjectured that the significant decrease in the TG concentrations in the female population after carotenoid intervention was linked to leptin. Leptin, a protein hormone secreted primarily by white adipose tissue, ameliorates elevated blood lipids produced by insulin resistance in obese patients. Carotenoids can increase leptin expression by acting on WAT mRNA, while oestrogens modulate the expression of leptin-specific receptors to increase leptin sensitivity. ${ }^{62-64}$ This finding may offer an explanation for the better intervention effect of carotenoids in women who have more oestrogen. Moreover, the studies with $\leq 12$ weeks did not show statistically significant changes between the intervention and control groups based on the outcomes of the subgroup analysis. The reason might be the lack of guidelines for carotenoid supplementation during the intervention time. We could only refer to the most common intervention duration of the supplemental trial included in this meta-analysis, which was 12 weeks. Simultaneously, developing guidelines for carotenoid supplementation in obese patients is urgently recommended.

This meta-analysis has some limitations. Some of the papers did not offer the sex distribution of the study population, so we could not include them in the subgroup analysis based on sex. Furthermore, most of the results were highly heterogeneous. This finding might be attributed to differences in subjects and geography, as well as the type of results. Most importantly, RCTs as reliable evidence of effectiveness, have not been widely conducted in studies of carotenoid supplementation in obese patients. The limited sample size of the included RCTs may bias the true effect of carotenoid supplementation on the obese population from the findings of this study.

\section{Conclusion}

Our study suggested that low serum carotenoids levels are a risk factor for overweight or obese subjects compared to normal weight individuals. Furthermore, carotenoid intervention showed a promising effect in overweight or obese subjects on anthropometric and lipid metabolic parameters by significantly reducing the body weight, BMI, WC and TC, and raising the HDL. Considering the limitations of this study, additional data from large clinical trials are needed.

\section{Author contributions}

NY, SMY and YPG designed the research; NY, SY and HW conducted the research; NY, HW, XTL and LW analyzed the data; NY, SY, YPG and WYH wrote the paper; NY had primary responsibility for the final content. All authors read and agreed with the final manuscript.

\section{Conflicts of interest}

The authors declare no conflicts of interest.

\section{Acknowledgements}

This work was supported by the National Natural Science Foundation of China (No. 81973129 and 81773412).

\section{References}

1 A. Afshin, M. H. Forouzanfar, M. B. Reitsma, P. Sur, K. Estep, A. Lee, L. Marczak, A. H. Mokdad, M. MoradiLakeh, M. Naghavi, J. S. Salama, T. Vos, K. H. Abate, C. Abbafati, M. B. Ahmed, Z. Al-Aly, A. Alkerwi, R. AlRaddadi, A. T. Amare, A. Amberbir, A. K. Amegah, E. Amini, S. M. Amrock, R. M. Anjana, J. Ärnlöv, H. Asayesh, A. Banerjee, A. Barac, E. Baye, D. A. Bennett, A. S. Beyene, S. Biadgilign, S. Biryukov, E. Bjertness, D. J. Boneya, I. Campos-Nonato, J. J. Carrero, P. Cecilio, K. Cercy, L. G. Ciobanu, L. Cornaby, S. A. Damtew, L. Dandona, R. Dandona, S. D. Dharmaratne, B. B. Duncan, B. Eshrati, A. Esteghamati, V. L. Feigin, J. C. Fernandes, T. Fürst, T. T. Gebrehiwot, A. Gold, P. N. Gona, A. Goto, T. D. Habtewold, K. T. Hadush, N. Hafezi-Nejad, S. I. Hay, M. Horino, F. Islami, R. Kamal, A. Kasaeian, S. V. Katikireddi, A. P. Kengne, C. N. Kesavachandran, Y. S. Khader, Y. H. Khang, J. Khubchandani, D. Kim, Y. J. Kim, Y. Kinfu, S. Kosen, T. Ku, B. K. Defo, G. A. Kumar, H. J. Larson, M. Leinsalu, X. Liang, S. S. Lim, P. Liu, A. D. Lopez, R. Lozano, A. Majeed, R. Malekzadeh, D. C. Malta, M. Mazidi, C. McAlinden, S. T. McGarvey, D. T. Mengistu, G. A. Mensah, G. B. M. Mensink, H. B. Mezgebe, E. M. Mirrakhimov, U. O. Mueller, J. J. Noubiap, C. M. Obermeyer, F. A. Ogbo, M. O. Owolabi, G. C. Patton, F. Pourmalek, M. Qorbani, A. Rafay, R. K. Rai, C. L. Ranabhat, N. Reinig, S. Safiri, J. A. Salomon, J. R. Sanabria, I. S. Santos, B. Sartorius, M. Sawhney, J. Schmidhuber, A. E. Schutte, M. I. Schmidt, S. G. Sepanlou, M. Shamsizadeh, S. Sheikhbahaei, M. J. Shin, R. Shiri, I. Shiue, H. S. Roba, D. A. S. Silva, J. I. Silverberg, J. A. Singh, S. Stranges, S. Swaminathan, R. Tabarés-Seisdedos, F. Tadese, B. A. Tedla, B. S. Tegegne, A. S. Terkawi, J. S. Thakur, M. Tonelli, R. Topor-Madry, S. Tyrovolas, K. N. Ukwaja, O. A. Uthman, M. Vaezghasemi, 
T. Vasankari, V. V. Vlassov, S. E. Vollset, E. Weiderpass, A. Werdecker, J. Wesana, R. Westerman, Y. Yano, N. Yonemoto, G. Yonga, Z. Zaidi, Z. M. Zenebe, B. Zipkin and C. J. L. Murray, Health Effects of Overweight and Obesity in 195 Countries over 25 Years, N. Engl. J. Med., 2017, 377, 13-27.

2 P. González-Muniesa, M. A. Mártinez-González, F. B. Hu, J. P. Després, Y. Matsuzawa, R. J. F. Loos, L. A. Moreno, G. A. Bray and J. A. Martinez, Obesity, Nat. Rev. Dis. Primers, 2017, 3, 17034.

3 World Health Organization, https:/www.who.int/newsroom/fact-sheets/detail/obesity-and-overweight.

4 D. W. Haslam and W. P. James, Obesity, Lancet, 2005, 366, 1197-1209.

5 L. Keaver, L. Webber, A. Dee, F. Shiely, T. Marsh, K. Balanda and I. J. Perry, Application of the UK foresight obesity model in Ireland: the health and economic consequences of projected obesity trends in Ireland, PLoS One, 2013, 8, e79827.

6 P. Langi, S. Kiokias, T. Varzakas and C. Proestos, Carotenoids: From Plants to Food and Feed Industries, Methods Mol. Biol., 2018, 1852, 57-71.

7 G. P. Lobo, J. Amengual, H. N. Li, M. Golczak, M. L. Bonet, K. Palczewski and J. von Lintig, Beta,beta-carotene decreases peroxisome proliferator receptor gamma activity and reduces lipid storage capacity of adipocytes in a beta, beta-carotene oxygenase 1-dependent manner, J. Biol. Chem., 2010, 285, 27891-27899.

8 A. Milani, M. Basirnejad, S. Shahbazi and A. Bolhassani, Carotenoids: biochemistry, pharmacology and treatment, Br. J. Pharmacol., 2017, 174, 1290-1324.

9 G. Martín-Pozuelo, I. Navarro-González, R. González-Barrio, M. Santaella, J. García-Alonso, N. Hidalgo, C. GómezGallego, G. Ros and M. J. Periago, The effect of tomato juice supplementation on biomarkers and gene expression related to lipid metabolism in rats with induced hepatic steatosis, Eur. J. Nutr., 2015, 54, 933-944.

10 S. L. Lay, P. Ferré and I. Dugail, Adipocyte cholesterol balance in obesity, Biochem. Soc. Trans., 2004, 32, 103-106.

11 R. Kakutani, S. Hokari, A. Nishino, T. Ichihara, K. Sugimoto, T. Takaha, T. Kuriki and T. Maoka, Effect of Oral Paprika Xanthophyll Intake on Abdominal Fat in Healthy Overweight Humans: A Randomized, Doubleblind, Placebo-controlled Study, J. Oleo Sci., 2018, 67, 11491162.

12 A. Iwata, S. Matsubara and K. Miyazaki, Beneficial effects of a beta-cryptoxanthin-containing beverage on body mass index and visceral fat in pre-obese men: Double-blind, placebo-controlled parallel trials, J. Funct. Foods, 2018, 41, 250-257.

13 Z. Pourahmadi, S. Mahboob, A. Saedisomeolia and M. T. Reykandeh, The Effect of Tomato Juice Consumption on Antioxidant Status in Overweight and Obese Females, Women Health, 2015, 55, 795-804.

14 F. Haidari, A. Hojhabrimanesh, B. Helli, S. S. Seyedian and K. Ahmadi-Angali, An energy-restricted high-protein diet supplemented with $\beta$-cryptoxanthin alleviated oxidative stress and inflammation in nonalcoholic fatty liver disease: a randomized controlled trial, Nutr. Res., 2020, 73, 15-26.

15 A. Stang, Critical evaluation of the Newcastle-Ottawa scale for the assessment of the quality of nonrandomized studies in meta-analyses, Eur. J. Epidemiol., 2010, 25, 603-605.

16 M. Abidov, Z. Ramazanov, R. Seifulla and S. Grachev, The effects of Xanthigen in the weight management of obese premenopausal women with non-alcoholic fatty liver disease and normal liver fat, Diabetes Obes. Metab., 2010, 12, 72-81.

17 M. Wiese, Y. Bashmakov, N. Chalyk, D. S. Nielsen, Ł. Krych, W. Kot, V. Klochkov, D. Pristensky, T. Bandaletova, M. Chernyshova, N. Kyle and I. Petyaev, Prebiotic Effect of Lycopene and Dark Chocolate on Gut Microbiome with Systemic Changes in Liver Metabolism, Skeletal Muscles and Skin in Moderately Obese Persons, BioMed Res. Int., 2019, 2019, 4625279.

18 H. D. Choi, Y. K. Youn and W. G. Shin, Positive effects of astaxanthin on lipid profiles and oxidative stress in overweight subjects, Plant Foods Hum. Nutr., 2011, 66, 363-369.

19 R. P. Paes-Silva, P. Gadelha, M. Lemos, C. Castro, I. K. G. Arruda and A. D. S. Diniz, Adiposity, inflammation and fat-soluble vitamins in adolescents, J. Pediatr., 2019, 95, 575-583.

20 I. R. Gunanti, G. C. Marks, A. Al-Mamun and K. Z. Long, Low serum concentrations of carotenoids and vitamin $\mathrm{E}$ are associated with high adiposity in Mexican-American children, J. Nutr., 2014, 144, 489-495.

21 L. de Souza Valente da Silva, G. Valeria da Veiga and R. A. Ramalho, Association of serum concentrations of retinol and carotenoids with overweight in children and adolescents, Nutrition, 2007, 23, 392-397.

22 R. O. Sarni, F. I. Suano de Souza, R. A. Ramalho, O. Schoeps Dde, C. Kochi, P. Catherino, M. C. Dias, C. F. Pessotti, L. C. Mattoso and F. A. Colugnat, Serum retinol and total carotene concentrations in obese preschool children, Med. Sci. Monit., 2005, 11, Cr510-Cr514.

23 K. Suzuki, T. Inoue, R. Hioki, J. Ochiai, Y. Kusuhara, N. Ichino, K. Osakabe, N. Hamajima and Y. Ito, Association of abdominal obesity with decreased serum levels of carotenoids in a healthy Japanese population, Clin. Nutr., 2006, 25, 780-789.

24 A. Hodge, J. Cunningham, L. Maple-Brown, T. Dunbar and K. O'Dea, Plasma carotenoids are associated with socioeconomic status in an urban Indigenous population: an observational study, BMC Public Health, 2011, 11, 76.

25 K. Suzuki, Y. Ito, J. Ochiai, Y. Kusuhara, S. Hashimoto, S. Tokudome, M. Kojima, K. Wakai, H. Toyoshima, K. Tamakoshi, Y. Watanabe, N. Hayakawa, M. Maruta, M. Watanabe, K. Kato, Y. Ohta and A. Tamakoshi, Relationship between obesity and serum markers of oxidative stress and inflammation in Japanese, Asian Pac. J. Cancer Prev., 2003, 4, 259-266.

26 J. E. Kimmons, H. M. Blanck, B. C. Tohill, J. Zhang and L. K. Khan, Associations between body mass index and the 
prevalence of low micronutrient levels among US adults, MedGenMed, 2006, 8, 59.

27 T. Decsi, D. Molnár and B. Koletzko, Reduced plasma concentrations of alpha-tocopherol and beta-carotene in obese boys, J. Pediatr., 1997, 130, 653-655.

28 K. J. Yeum, S. L. Booth, R. Roubenoff and R. M. Russell, Plasma carotenoid concentrations are inversely correlated with fat mass in older women, J. Nutr. Health Aging, 1998, 2, 79-83.

29 P. Berbis, [Retinoids: mechanisms of action], Ann. Dermatol. Venereol., 2010, 137(Suppl 3), S97-103.

30 M. L. Bonet, J. A. Canas, J. Ribot and A. Palou, Carotenoids and their conversion products in the control of adipocyte function, adiposity and obesity, Arch. Biochem. Biophys., 2015, 572, 112-125.

31 L. F. Andersen, D. R. Jacobs Jr., M. D. Gross, P. J. Schreiner, O. Dale Williams and D. H. Lee, Longitudinal associations between body mass index and serum carotenoids: the CARDIA study, Br. J. Nutr., 2006, 95, 358-365.

32 E. J. Schwarz, M. J. Reginato, D. Shao, S. L. Krakow and M. A. Lazar, Retinoic acid blocks adipogenesis by inhibiting C/EBPbeta-mediated transcription, Mol. Cell. Biol., 1997, 17, 1552.

33 Y. Kamei, T. Kawada, J. Mizukami and E. Sugimoto, The prevention of adipose differentiation of 3 T3-L1 cells caused by retinoic acid is elicited through retinoic acid receptor alpha, Life Sci., 1994, 55, PL307.

34 C. H. Saely, K. Geiger and H. Drexel, Brown versus white adipose tissue: a mini-review, Gerontology, 2012, 58, 15-23.

35 A. Palou and M. L. Bonet, Challenges in obesity research, Nutr. Hosp., 2013, 28 Suppl 5, 144-153.

36 W. S. Blaner, Vitamin A Signaling and Homeostasis in Obesity, Diabetes, and Metabolic Disorders, Pharmacology?, Therapeutics, 2019, 197, 153-178.

37 A. Palou, C. Picó and M. L. Bonet, Nutritional potential of metabolic remodelling of white adipose tissue, Curr. Opin. Clin. Nutr. Metab. Care, 2013, 16, 650-656.

38 T. Montanari, N. Pošćić and M. Colitti, Factors involved in white-to-brown adipose tissue conversion and in thermogenesis: a review, Obesity, 2017, 18, 495-513.

39 M. Murholm, M. S. Isidor, A. L. Basse, S. Winther, C. Sørensen, J. Skovgaard-Petersen, M. M. Nielsen, A. S. Hansen, B. Quistorff and J. B. Hansen, Retinoic acid has different effects on UCP1 expression in mouse and human adipocytes, BMC Cell Biol., 2013, 14, 41.

40 D. Mathis, Immunological goings-on in visceral adipose tissue, Cell Metab., 2013, 17, 851-859.

$41 \mathrm{~J}$. Ferrante and W. Anthony, Macrophages, fat, and the emergence of immunometabolism, J. Clin. Invest., 2013, 123, 4992-4993.

42 J. Amengual, E. Gouranton, Y. G. van Helden, S. Hessel, J. Ribot, E. Kramer, B. Kiec-Wilk, U. Razny, G. Lietz, A. Wyss, A. Dembinska-Kiec, A. Palou, J. Keijer, J. F. Landrier, M. L. Bonet and J. von Lintig, Beta-carotene reduces body adiposity of mice via BCMO1, PLoS One, 2011, 6, e20644.
43 P. C. Calder, N. Ahluwalia, F. Brouns, T. Buetler, K. Clement, K. Cunningham, K. Esposito, L. S. Jönsson, H. Kolb, M. Lansink, A. Marcos, A. Margioris, N. Matusheski, H. Nordmann, J. O'Brien, G. Pugliese, S. Rizkalla, C. Schalkwijk, J. Tuomilehto, J. Wärnberg, B. Watzl and B. M. Winklhofer-Roob, Dietary factors and low-grade inflammation in relation to overweight and obesity, Br. J. Nutr., 2011, 106 Suppl 3, S5-78.

44 S. B. Kritchevsky, A. J. Bush, M. Pahor and M. D. Gross, Serum carotenoids and markers of inflammation in nonsmokers, Am. J. Epidemiol., 2000, 152, 1065-1071.

45 T. P. Erlinger, E. Guallar, E. R. Miller 3rd, R. StolzenbergSolomon and L. J. Appel, Relationship between systemic markers of inflammation and serum beta-carotene levels, Arch. Intern. Med., 2001, 161, 1903-1908.

46 S. Thomas-Valdés, M. Tostes, P. C. Anunciação, B. P. da Silva and H. M. P. Sant'Ana, Association between vitamin deficiency and metabolic disorders related to obesity, Crit. Rev. Food Sci. Nutr., 2017, 57, 3332-3343.

47 T. Bohn, Carotenoids and Markers of Oxidative Stress in Human Observational Studies and Intervention Trials: Implications for Chronic Diseases, Antioxidants, 2019, 8, 179.

48 M. L. Bonet, J. A. Canas, J. Ribot and A. Palou, Carotenoids and their conversion products in the control of adipocyte function, adiposity and obesity, Arch. Biochem. Biophys., 2015, 572, 112-125.

49 R. Rühl, Effects of dietary retinoids and carotenoids on immune development, Proc. Nutr. Soc., 2007, 66, 458-469.

50 F. Marchildon, C. St-Louis, R. Akter, V. Roodman and N. Wiper-Bergeron, Transcription Factor Smad3 Is Required for the Inhibition of Adipogenesis by Retinoic Acid, J. Biol. Chem., 2010, 285, 13274-13284.

51 D. C. Berry, D. Desantis, H. Soltanian, C. M. Croniger and N. Noy, Retinoic Acid Upregulates Preadipocyte Genes to Block Adipogenesis and Suppress Diet-Induced Obesity, Diabetes, 2012, 61, 1112-1121.

52 F. Serra, M. L. Bonet, P. Puigserver, J. Oliver and A. Palou, Stimulation of uncoupling protein 1 expression in brown adipocytes by naturally occurring carotenoids, Int. J. Obes. Relat. Metab. Disord., 1999, 23, 650-655.

53 R. Alvarez, M. L. Checa, S. Brun, O. Viñas, T. Mampel, R. Iglesias, M. Giralt and F. Villarroya, Both retinoic-acidreceptor- and retinoid-X-receptor-dependent signalling pathways mediate the induction of the brown-adiposetissue-uncoupling-protein-1 gene by retinoids, Biochemical Journal, 2000, 345(Pt 1), 91-97.

54 P. P. Toth, P. J. Barter, R. S. Rosenson, W. E. Boden, M. J. Chapman, M. Cuchel, R. B. D'Agostino Sr., M. H. Davidson, W. S. Davidson, J. W. Heinecke, R. H. Karas, A. Kontush, R. M. Krauss, M. Miller and D. J. Rader, High-density lipoproteins: a consensus statement from the National Lipid Association, J. Clin. Lipidol., 2013, 7, 484-525.

55 D. C. Goff Jr., D. M. Lloyd-Jones, G. Bennett, S. Coady, R. B. D'Agostino Sr., R. Gibbons, P. Greenland, D. T. Lackland, D. Levy, C. J. O'Donnell, J. G. Robinson, 
J. S. Schwartz, S. T. Shero, S. C. Smith Jr., P. Sorlie, N. J. Stone and P. W. F. Wilson, 2013 ACC/AHA guideline on the assessment of cardiovascular risk: a report of the American College of Cardiology/American Heart Association Task Force on Practice Guidelines, J. Am. Coll. Cardiol., 2014, 63, 2935-2959.

56 B. G. Nordestgaard and A. Varbo, Triglycerides and cardiovascular disease, Lancet, 2014, 384, 626-635.

57 I. N. Baranova, T. G. Vishnyakova, A. V. Bocharov, R. Kurlander, Z. Chen, M. L. Kimelman, A. T. Remaley, G. Csako, F. Thomas, T. L. Eggerman and A. P. Patterson, Serum amyloid A binding to CLA-1 (CD36 and LIMPII analogous-1) mediates serum amyloid A protein-induced activation of ERK1/2 and p38 mitogen-activated protein kinases, J. Biol. Chem., 2005, 280, 8031-8040.

58 J. McEneny, L. Wade, I. S. Young, L. Masson, G. Duthie, A. McGinty, C. McMaster and F. Thies, Lycopene intervention reduces inflammation and improves HDL functionality in moderately overweight middle-aged individuals, J. Nutr. Biochem., 2013, 24, 163-168.
59 B. Klop, J. W. Elte and M. C. Cabezas, Dyslipidemia in obesity: mechanisms and potential targets, Nutrients, 2013, 5, 1218-1240.

60 E. Gouranton, C. Thabuis, C. Riollet, C. MalezetDesmoulins, C. El Yazidi, M. J. Amiot, P. Borel and J. F. Landrier, Lycopene inhibits proinflammatory cytokine and chemokine expression in adipose tissue, J. Nutr. Biochem., 2011, 22, 642-648.

61 A. A. Knowlton and A. R. Lee, Estrogen and the cardiovascular system, Pharmacol. Ther., 2012, 135, 54-70.

62 D. J. Clegg, L. M. Brown, S. C. Woods and S. C. Benoit, Gonadal hormones determine sensitivity to central leptin and insulin, Diabetes, 2006, 55, 978-987.

63 S. R. Ladyman and D. R. Grattan, Suppression of leptin receptor messenger ribonucleic acid and leptin responsiveness in the ventromedial nucleus of the hypothalamus during pregnancy in the rat, Endocrinology, 2005, 146, 3868-3874.

64 R. A. Lobo, Metabolic syndrome after menopause and the role of hormones, Maturitas, 2008, 60, 10-18. 